\title{
The Impact of Microsoft Teams and Zoom on Improving English Teaching During the COVID-19 Pandemic From the Perspective of Palestinian English Teachers
}

\author{
Mohamanal Hamarsha ${ }^{1}$, Tahani Rsharat ${ }^{2}$ \\ ${ }^{1}$ Master Degree in Methods of Teaching English, Faculty of Educational Sciences and Teachers' Training, An Najah National University \\ palestinemanalh.naje@outlookcom \\ ${ }^{2} \mathrm{Ph}$ D researcher at Faculty of Major Language Studies, UniversitiSains Islam Malaysia, Malaysia, \\ tahanibsharat@raudah.usim.edu.my
}

\begin{abstract}
The study considered the Palestinian teachers in Palestine schools' opinions on the influence of Zoom and Microsoft Teams on the teaching/learning process. The teachers were asked applications they prefer, most of the teachers showed a clear preference for the Zoom app. The teachers also stated the positive impression of these tools on the educational process improvement and students' experience enhancement, because of the features these applications have, as it enables students to refer to the lessons whenever they need. The teachers' views of the features of Zoom and Teams are associated with the easiness, recording feature, easy communication channels between the teachers and their students during the lessons and lectures. Supplementary research should be carried out in the field of the influence of e-learning on students' thinking skills and achievement as well as uncovering the aspects of benefits weaknesses to remedy it as a method to provide a learning environment for the students.
\end{abstract}

Keywords: E learning, Palestinian teachers, Zoom, Microsoft. Teams, COVID 19

\section{Introduction}

The Corona virus emerged and spread over the world, paralyzing all institutions in the country, particularly educational institutions at all levels. As a precautionary measure against this fatal illness, several countries were obliged to suspend studies and resort to quarantine. Algeria swiftly built up platforms and websites to allow students to complete their studies via remote education. Therefore, The Ministry of National Education and the Ministry of Higher Education have taken many steps to adjust to the current scenario (Kim, 2020). likewise, Palestine was entirely quarantined for three months, from March to June. The academic year was postponed due to the spread of the Coronavirus COVID 19, and then due to all of these hard conditions and the state of emergency, the academic year was postponed again. The Ministry of Education started giving teachers courses on the Zoom program to activate Elearning in all Palestinian cities, and after that, courses on the Microsoft Teams program were given due to its high specifications to activate the educational process and solve the problem in the presence of the Coronavirus COVID 19 and its spread so far (Bsharat\&Behak, 2020).

The installation of a quarantine as a result of the latest Coronavirus outbreak has presented numerous obstacles to our country's education and higher education systems, including continuing education, maintaining quality, and establishing equity, as well as amongst students of different social groups, In view of the disruption of schools, institutes, and colleges, as well as the shift to a remote education system or "digital" or "electronic" education, the system of education and higher education in times of sanitary isolation or home quarantine raises issues, the educational system's preparation and accessible skills, in which educational values and components collide with the virus's rising conditions, which alienated teachers from students and students, and what these conditions impose on changing pedagogical work mechanisms inside The consequences of schools, institutions, and colleges on students and students, as well as the requirement of employing current and technical tools for online education (Pokhrel \& Chhetri, 2021).

Distance learning has become a much more engaging and involved learning experience in 2019. (Agostinelli, 2019). The teachers are the important participants in the successful implementation of distance education (Orhan \& Beyhan, 2020). Orhan and Beyhan (2020) proposed several ideas for improving the quality of distant education. First, the objectives and content of the education program course, as well as the teaching methodologies and techniques, should be decided. Second, the technology that will be used to deliver the information must be decided. Third, learners' responsibilities during the learning process must be determined since they must be in command of their own learning. Tolga (2015) agrees that students' obligations must be identified in order for distant learning to be successful. According to Orhan and Beyhan (2020), the success of distant learning can be influenced by a variety of factors, including technical concerns such as internet connectivity and picture/audio issues The interaction between the teacher 
and the learner is another component that determines the quality of the distant learning process. Videoconferencing tools can be used to create a synchronous contact between lecturers and students (Ghazal et al., 2015).

\section{Literature Review}

There are a large variety of videoconferencing systems available today (Clopper, Baccei, \& Sel, 2020) that can be used as a distant education mediation tool. Video conferencing technology can be characterized as a means of communication in which linked individuals can share audio and visual facilities in real time (Al-Samarraie, 2019), and registered users can transfer slides, files, texts, and images via the platform being utilized (Al-Samarraie, 2019). (Krutka \& Carano, 2016). Videoconferencing has become more popular as a learning tool (Al-Samarraie, 2019), especially when formal schooling is not feasible. The reason for this is because it enables for synchronous communication (Lenkaitis, Calo, \& Venegas Escobar, 2019) and effective interaction (Al-Samarraie, 2019) between teachers and students or between students and their peers. Also, Parra\&Granda (2021) compared two of the most popular virtual university class meeting options, finding that Zoom was substantially more appealing than Webex, despite no significant differences in the classic aspects of usability or user experience. Similarly, teachers and students feel that these tools are a big assistance in virtual classes (Del RioChillcce et al., 2021), demonstrating favorable attitudes toward videoconferencing (Wea\& Kuki, 2021). Demir and Akpinar's (2018) quasi-experimental study on the effect of mobile learning applications on undergraduate students' academic achievement, attitudes toward mobile learning, and animation development levels found that mobile learning may promote students' academic achievement, with the study showing that students valued mobile learning as a method that could significantly increase their motivation.

Students were satisfied with zoom video lectures for the following reasons, according to Kim (2020): "enhanced interest in and motivation toward learning," "self-directed learning, " "active interaction, " "easy of access, " and "ease of knowledge retrieval. "At the same time, the survey discovered that some students dislike zoom video lectures because of "mechanical problems or defects, " "bad audio quality, " and "the necessity to integrate tailored functions for efficient classes. Zoom video lectures must be augmented in practice with automatic attendance processing, easy data upload and download, and better video screen management.

The abrupt shift to e-teaching/ learning is undoubtedly difficult. According to Jain, Lall, and Singh (2021), the shift to online education has exacerbated inequities between private and public institutions. This is exacerbated by the fact that pupils from economically disadvantaged backgrounds have become difficult to reach, and teachers are unsure how to help these students who are also profoundly affected by the pandemic. Teachers have not been trained in online pedagogies, according to the statistics. Ed-Tech firms have stepped in, pitching themselves as a remedy for the problem, with further implications for teachers' professions, standing, and livelihoods. Ed-Tech solutions, on the other hand, are ineffective for hard-to-reach kids and teachers in schools serving hard-to-reach areas.

Carretero et al. (2021) gathered information from a variety of sources, including students, parents, teachers, and school officials, to gain varied viewpoints on the remote education experience. The study found that, given the current state of infrastructure and equipment accessibility, full-time remote education would exacerbate existing inequities, particularly for specific groups of children who were unable to attend lessons offered online. We also discovered that during distant schooling, parents played an important part in their children's learning. This is especially true for pupils in primary school or youngsters with special needs who require more of their assistance. Parents served as both motivators and facilitators of learning, particularly when teachers were unavailable. However, parents' readiness to play these responsibilities and the quantity of support received from schools were not always seen favorably, which could contribute to rising inequities in educational access. Teachers found it more difficult to monitor pupils' learning progress during remote schooling, according to the researchers. In addition, teachers waited longer than normal to offer comments, which had a negative impact on students learning performance. In addition, self-and peer-evaluation were underutilized as assessment strategies.

Furthermore, Mohan et al. (2020) discovered that the abrupt shift to distant learning had a negative influence on group work, particularly practical work, as well as student participation and engagement. Some of these effects appear to have been more prominent at schools with less access to high-speed broadband, DEIS schools, and schools in lowincome neighborhoods. Uncertainty around State examinations, issues linked to working at home, and insufficient home internet speed were deemed to be some of the most pressing challenges experienced by both teachers and students. Slow internet speed at home was cited as a concern by a higher percentage of schools in locations with less broadband availability as well as schools in areas with lower household income, showing a two-dimensional problem of local broadband availability and access to appropriate devices. The ability of schools to cover practical components of the curriculum was found to be considerably limited, and final presentations and open-book exams were found to be the most common means for assessing pupils at the end of the year.

A study conducted in Australia and New Zealand revealed a profession under extreme duress - dealing with unfamiliar technologies and teaching methods, juggling increased preparation demands, fretting about a lack of social contact with students and colleagues, and fearing for the educational and psychological well-being of students, particularly those in early primary school (Flack et al., 2020).

Despite all of the challenges associated with the rapid transition to electronic learning/teaching, Basilaia \& Kvavadze's (2020) findings show that the rapid transition to an online form of education was a success, and the learned experience can be applied in the future. 
Karthikeyan (2020) investigated Microsoft Teams from the standpoint of a bachelor's degree program student. From the perspective of students, this study reveals that Microsoft Teams is helpful and simple to use for completing critical components of learning and knowledge acquisition, as well as pointing out areas where user-friendliness might be enhanced. As a result, the current study not only aids academics in comprehending the digital learning platforms utilized in higher education using Microsoft Teams as a model, but also provides crucial recommendations and proposals for improving such platforms in the future for a better learning experience.

Zoom has been found to be the most efficient platform among videoconferencing solutions, according to Lenkaitis, Calo, and Venegas Escobar (2019). They cited its userfriendliness, free capacity for recording movies up to 40 minutes in length, and the fact that only one person is required to create an account as factors (Lenkaitis et al., 2019). This is something that Nash (2020) agrees with. Similar reasons were noted by Gray, Wong-Wylie, Rempel, and Cook (2020), who also mentioned password security for confidentiality, while Kohnke and Moorhouse (2020) mentioned annotation tool, breakout rooms, and polls.

Clopper, Baccei, and Sel's (2020) study comparing Zoom and Microsoft teams based on user feedback revealed that Zoom obtained a higher overall rating. The literature on videoconferencing in the context of second language acquisition found that it allows learners to practice their second language while also allowing them to participate actively in virtual copresence and knowledge building processes (Lenkaitis, 2020).

Many studies in the literature looked at videoconferencing in the education area from a variety of angles, including telecollaboration, intercultural competency development, pre-service teacher education, teacher perceptions, and improving student engagement, achievement, and motivation (Ayoub, 2019; Benitt, 2019; Lenkaitis, 2020; Yu, 2018). Among them, some were particularly interested in Zoom's videoconferencing (Ayoub, 2019; Lenkaitis, 2020).
Furthermore, (Bsharat\&Behak, 2020) stated that the most important feature of Ms. Teams is that it allows students to share files and content, as well as screen sharing options that allow teachers to display whatever they want during a class, indicating that it creates an interactive atmosphere between students, teachers, and the community inside an institution. Where e-learning is a critical component in the process of shifting the focus of education to the student by equipping him with 21 st-century skills, which benefits the community by producing a generation capable of taking on responsibilities. The study also discovered that, regardless of their gender, participants have similar sentiments toward the impact of Microsoft Teams' App in Enhancing TeachingLearning English during the Coronavirus (COVID-19), as indicated in the table below. The impact of Microsoft Teams' App in Enhancing Teaching-Learning English During Coronavirus (COVID-19) disparities amongst participants due to age differences demonstrated a common view with no variances in the influence of Microsoft Teams among them.

\section{Methodology}

\subsection{Design}

A quantitative descriptive analytical approach was implemented. The descriptive method is one of the most important and most common scientific research methods in scientific research. Through the descriptive-analytical approach, the researcher can study the reality very accurately, as the researcher identifies the reasons that led to the occurrence of the phenomenon and contributes to discovering solutions to it. Through the descriptive analytical approach, the researcher analyses the studied phenomenon, and after he finishes studying this phenomenon, he makes comparisons between it and other phenomena and then analyses them.

\subsection{Population and sampling}

The research target population was English language teachers located in Jenin city. The sample was chosen conveniently and encompassed (50) teachers. (See Fig. I below).

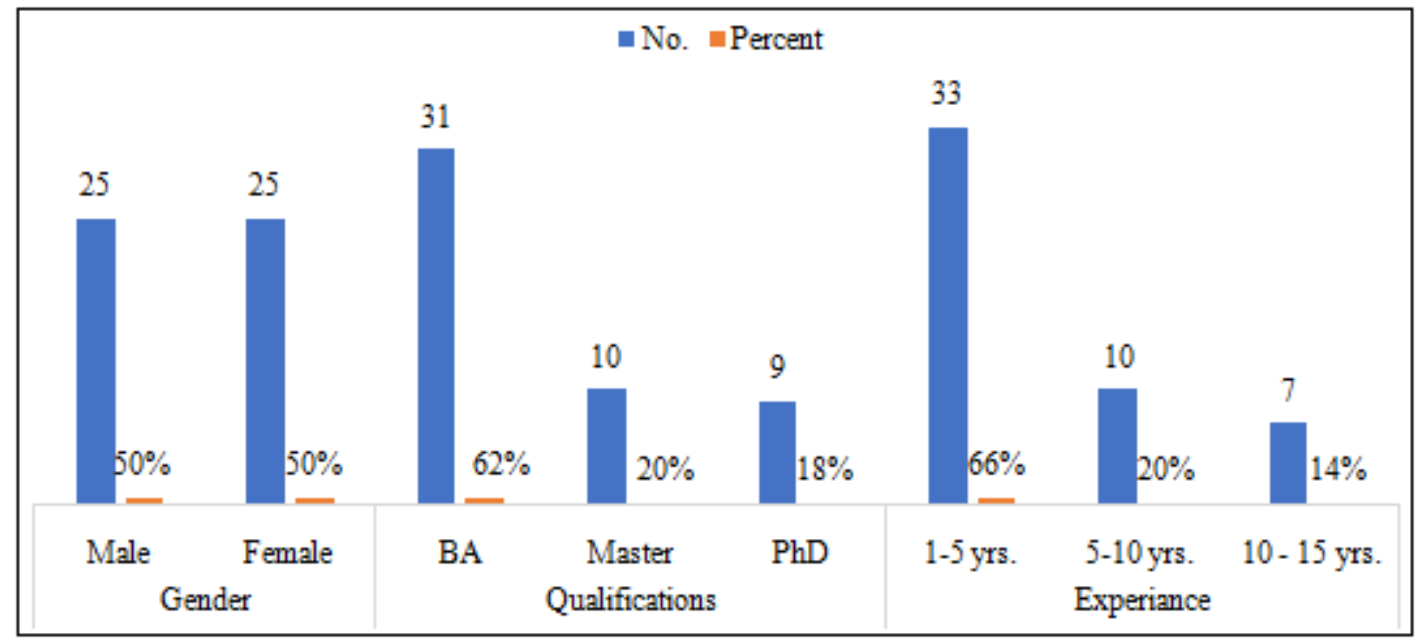

Figure I: Characteristics of the study sample 
As the figure shows, the sample is distributed equally by half for both genders. Most of the respondents 31 (62\%) were holders of BA degrees, 10 (20\%) were MA's holders, and $9(18 \%)$ reported holding a $\mathrm{PhD}$. Also, $33(66 \%)$ have work experience between 1 and 5 years, compared to 10 (20\%) who have 5-10 years of experience and 7 (14\%) who has been in-service for 10-15 years.

\subsection{Instrumentation}

The participants filled a self-administered questionnaire consisted of (18) items. The questionnaire responses were assessed using 5-point Likert scale (1-strongly agree, 2agree, 3-neutral, 4-disagree, 5-strongly disagree). The questionnaire was distributed using google forms through a link generated by the site and then shared among participants. The validity of the questionnaire was examined using Cronbach alpha that was (0.76).

\subsection{Data analysis}

The data was analysed using SPSS v.23. The analytical methods included performing descriptive analysis. The independent sample t-test was performed to detect differences between male and female participants. The analysis of variance (One-way anova) was utilized to explore the differences, if any, between the participants depending on their experience and qualification.

\section{Results}

There is no doubt that the tremendous and accelerating technological progress in all areas of economic, industrial, commercial and educational life has produced several terms aimed at benefiting from these technologies in the field of education, and these terms include: the virtual environment, schools and electronic laboratories, learning management systems, electronic courses, e-learning and educational platforms This forced educational institutions to reconsider educational plans and strategies, and work to integrate modern technologies into the educational system.

This research exploredthe impact of Microsoft Teams App and Zoom App in enhancing teaching/learning of English during (COVID-19) pandemic from the English teachers' perspectives in Jenin city. The participants were asked about their preferable videoconferencing application, where the majority voted for Zoom.

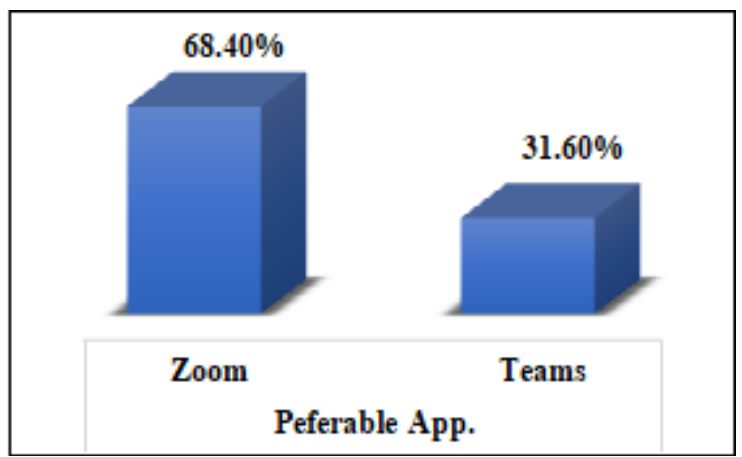

Figure 2: The teachers preferred videoconferencing application

Table 1: Means and standard deviations of the participants' responses to the questionnaire items

\begin{tabular}{|c|c|c|c|}
\hline Item & Mean & $\mathrm{SD}$ & Degree \\
\hline $\begin{array}{l}\text { Microsoft Teams and Zoom apps made it easier for the teachers to prepare and deliver } \\
\text { educational presentations. }\end{array}$ & 4.48 & .735 & Strongly agree \\
\hline $\begin{array}{l}\text { Microsoft Teams and Zoom apps captured the students' attention and encouraged them to pursue } \\
\text { their studies. }\end{array}$ & 4.46 & .734 & Strongly agree \\
\hline $\begin{array}{c}\text { Microsoft Teams and Zoom apps gave the teachers lots of room to save and organize teaching } \\
\text { files for each grade and student. }\end{array}$ & 4.36 & .776 & Strongly agree \\
\hline Students may use Microsoft Teams and Zoom apps to share files and material. & 4.38 & .753 & Strongly agree \\
\hline $\begin{array}{c}\text { Microsoft Teams and Zoom apps aided in the development of new virtual classrooms that are } \\
\text { both modern and advanced }\end{array}$ & 4.42 & .730 & Strongly agree \\
\hline $\begin{array}{c}\text { Microsoft Teams and Zoom apps provided screen-sharing features that give teachers the } \\
\text { flexibility to show whatever they want during a lesson }\end{array}$ & 4.38 & .830 & Strongly agree \\
\hline $\begin{array}{l}\text { By default, Microsoft Teams and Zoom apps provided options for recording attendee and } \\
\text { absence lists }\end{array}$ & 4.42 & .672 & Strongly agree \\
\hline $\begin{array}{l}\text { Microsoft Teams and Zoom apps allowed educators from all over the world to share their } \\
\text { thoughts and experiences on a common platform. }\end{array}$ & 4.38 & .635 & Strongly agree \\
\hline $\begin{array}{c}\text { Microsoft Teams and Zoom apps allow teachers to record lectures and lessons and go over what } \\
\text { they missed. }\end{array}$ & 4.52 & .646 & Strongly agree \\
\hline Total score & 4.42 & .510 & Strongly agree \\
\hline
\end{tabular}

The previous table shows the respondents views on the impact of Microsoft Teams and Zoom apps in enhancing teaching/learning of English during (COVID-19) pandemic from the English teachers' perspectives in Jenin city. The respondents reported high agreement on these platforms impact on enrichment of the teaching/learning processes $(\mathrm{M}=4.42, \mathrm{SD}=0.51)$. This is quite significant considering the rapid transformation from traditional face to face teaching/learning into electronic teaching/learning environment that was also challenging for the educational parties involved.

According to the teachers' responses, the feature mostly valued was the enabling of teachers to record, save and share the lectures and lessons with their students, allowing all participants to review the lesson and refer to it whenever 
needed $\quad(\mathrm{M}=4.52, \quad \mathrm{SD}=0.64)$. Another significant characteristic was the easiness that Microsoft Teams and Zoom apps made for the teachers to prepare and deliver educational presentations $(\mathrm{M}=4.48, \mathrm{SD}=0.73)$, which also means providing both, teachers and students, with interactive environment that motivate both to continue the teaching/learning process.

There are no statistically significant differences at the level of $(\alpha=0.05)$ in the impact of Microsoft Teams App and Zoom App in enhancing teaching/learning of English during (COVID-19) pandemic from the English teachers' perspectives in Jenin city related to gender.

The independent sample t-test was carried out to identify any differences in the impact of Microsoft Teams App and Zoom App in enhancing teaching/learning of English during (COVID-19) pandemic from the English teachers' perspectives in Jenin city between male and female teachers.

Table 2: The independent sample t-test analysis outcomes

\begin{tabular}{|c|c|c|c|c|c|}
\hline & Gender & No. & Mean & Std. Deviation & Sig. \\
\hline \multirow{2}{*}{ Total score } & Male & 25 & 4.6267 & .41806 & \multirow{2}{*}{0.980} \\
\cline { 2 - 6 } & Female & 25 & 4.2178 & .51965 & \\
\hline
\end{tabular}

The results presented in the above table confirm the presumption that there are no statistically significant differences at the level of $(\alpha=0.05)$ in the impact of Microsoft Teams App and Zoom App in enhancing teaching/learning of English during (COVID-19) pandemic from the English teachers' perspectives in Jenin city related to gender, since the significance is $0.9>0.05$.

There are no statistically significant differences at the level of $(\alpha=0.05)$ in the impact of Microsoft Teams App and Zoom App in enhancing teaching/learning of English during (COVID-19) pandemic from the English teachers' perspectives in Jenin city related to qualification.

The analysis of variance (One-Way ANOVA) was performed to detect any differences in the impact of Microsoft Teams App and Zoom App in enhancing teaching/learning of English during (COVID-19) pandemic from the English teachers' perspectives in Jenin city between the teachers' different qualifications.

Table 2: The One-Way ANOVA analysis outcomes

\begin{tabular}{|c|c|c|c|c|c|}
\hline & Sum of Squares & df & Mean Square & F & Sig. \\
\cline { 1 - 4 } Between Groups & .578 & 2 & .289 & & \\
Within Groups & 12.188 & 47 & .259 & 1.114 & .337 \\
\hline Total & 12.765 & 49 & & & \\
\hline
\end{tabular}

The results presented in the above table confirm the presumption that there are no statistically significant differences at the level of $(\alpha=0.05)$ in the impact of Microsoft Teams App and Zoom App in enhancing teaching/learning of English during (COVID-19) pandemic from the English teachers' perspectives in Jenin city related to qualification, since the significance is $0.3>0.05$.

There are no statistically significant differences at the level of $(\alpha=0.05)$ in the impact of Microsoft Teams App and Zoom App in enhancing teaching/learning of English during (COVID-19) pandemic from the English teachers' perspectives in Jenin city related to qualification.

The analysis of variance (One-Way ANOVA) was performed to detect any differences in the impact of Microsoft Teams App and Zoom App in enhancing teaching/learning of English during (COVID-19) pandemic from the English teachers' perspectives in Jenin city between the teachers' different qualifications.

Table 3: The One-Way ANOVA analysis outcomes

\begin{tabular}{|c|c|c|c|c|c|}
\hline & Sum of Squares & df & Mean Square & F & Sig. \\
\cline { 1 - 4 } Between Groups & .759 & 2 & .380 & & \\
\cline { 1 - 4 } Within Groups & 12.006 & 47 & .255 & 1.487 & .237 \\
\hline Total & 12.765 & 49 & & & \\
\hline
\end{tabular}

The results presented in the above table confirm the presumption that there are no statistically significant differences at the level of $(\alpha=0.05)$ in the impact of Microsoft Teams App and Zoom App in enhancing teaching/learning of English during (COVID-19) pandemic from the English teachers' perspectives in Jenin city related to experience, since the significance is $0.2>0.05$.

\section{Discussion}

The study investigated the Palestinian teachers in schools' views on the influence of Zoom and Microsoft Teams on the teaching/learning process. The teachers were queried about the videoconferencing application they prefer, mostof the teachers showed clear preference of Zoom app, in accordance with Parra \&Granda (2021), (Del Rio-Chillcce et al., 2021) Karthikeyan (2020), Lenkaitis, Calo and Venegas Escobar (2019), Clopper, Baccei and Sel's (2020) and (Wea\& Kuki, 2021). The outcome is not surprising considering the amount of research that explored the various E-education applications, where Zoom is the primary choice of the teachers across the educational levels.

The teachers also reported positive impact of these tools on the educational process enrichment and students' experience enhancement, because of the features these applications have, as it enables students to refer to the lessons whenever they need. This outcome accords with Kim (2020) and Basilaia \& Kvavadze (2020).

The teachers' views of the features of Zoom and Teams are related to the easiness, recording feature, easy communication channels between the teachers and their students during the lessons and lectures. The outcomes align with (Lenkaitis et al., 2019), Nash (2020), Gray, WongWylie, Rempel and Cook (2020) and Kohnke and Moorhouse (2020) results that also highlighted another feature; the fact that it needs only one person to create an account. Such characteristics are crucial for the educational process to continue as smooth as possible, the complicity and difficulty of application will absolutely hinder the teaching/learning, resulting in futile education.

\section{Conclusion}

The accelerated scientific and technical progress in various fields makes it imperative for countries to continue 
developing their various systems, especially educational systems, including the development of curricula, processes and elements of teaching and learning, methods of implementation, and evaluation methods in line with the needs of society and fulfilling the requirements of individuals. Thus, the role entrusted to the bodies responsible for education is to prepare strategic plans and design study programs that will develop the educational and educational process; To prepare future generations who possess the knowledge and skill to coexist with the era of globalization of the twenty-first century, and to contribute to the progress and advancement of their societies.

Zoom platform is praised by the teachers and also the growing literature in the field of education and e-learning, so, schools and administration are highly recommended to adopt Zoom over Teams for its unique features that eases the teaching/learning process and minimizes the burden on the teachers when the lesson needs re-instruction as it is recorded by the teachers and easily accessed by the learners. In addition, the teachers should be engaged in e-learning training courses to elevate their educational skills to meet the educational process requirements and achieve the $21^{\text {st }}$ century skills supposed to be possessed by the teachers.

Moreover, further research should be carried out in the field of influence of e-learning on students' thinking skills and achievement as well as uncovering the aspects of disadvantage to remedy it as method to provide profundo learning environment for the students.

\section{Acknowledgement}

The researchers would like to thank all the teachers who participated in the study and the conference committee for providing the chance to participate.

\section{References}

[1] Agostinelli Jr, M. D. (2019). From distance education to online education: a review of the literature.

[2] Ayoub, J. (2019). Effective Use of Zoom Sessions (a Synchronous Learning Strategy) to Foster Success and Motivation of Lebanese University Students in Bekaa: A Case Study. Available at https: //www.awraqthaqafya. com/601/

[3] Basilaia, G., \&Kvavadze, D. (2020). Transition to online education in schools during a SARS-CoV-2 Coronavirus (COVID-19) pandemic in Georgia. Pedagogical Research, 5 (4), em0060.

[4] Benitt, N. (2019). Campus Meets Classroom: Video Conferencing and Reflective Practice in Language Teacher Education. European Journal of Applied Linguistics and TEFL, 8 (2), 121-139.

[5] Carretero, S., Mägi, E., Bessios, A., Napierala, J., Gonzalez-Vazquez, I., Triquet, K.,. . . \& RobledoBottcher, N. (2021). What Did We Learn from Schooling Practices during the COVID-19 Lockdown? Insights from Five EU Countries. JRC Science for Policy Report. European Commission.

[6] Clopper, A. J., Baccei, E. C., \&Sel, T. J. (2020). An evaluation of Zoom and Microsoft Teams video conferencing software with network packet loss and latency. Interactive Qualifying Projects (All Years).

[7] Del Rio-Chillcce, A., Jara-Monge, L., \& AndradeArenas, L. (2021). Analysis of the Use of Videoconferencing in the Learning Process During the Pandemic at a University in Lima. International Journal of Advanced Computer Science and Applications (IJACSA), 12 (5), 870-878.

[8] Demir, K., \&Akpinar, E. (2018). The Effect of Mobile Learning Applications on Students' Academic Achievement and Attitudes toward Mobile Learning. Malaysian Online Journal of Educational Technology, 6 (2), 48-59.

[9] Flack, C. B., Walker, L., Bickerstaff, A., Earle, H., \& Margetts, C. (2020). Educator perspectives on the impact of COVID-19 on teaching and learning in Australia and New Zealand. Pivot Professional Learning.

[10] Ghazal, S., Samsudin, Z., \&Aldowah, H. (2015). Students' perception of synchronous courses using skype-based video conferencing. Indian Journal of Science and Technology, 8 (30), 1-9.

[11] Gray, L. M., Wong-Wylie, G., Rempel, G. R., \& Cook, K. (2020). Expanding qualitative research interviewing strategies: Zoom video communications. The Qualitative Report, 25 (5), 1292-1301.

[12] Jain, S., Lall, M., \& Singh, A. (2021). Teachers' voices on the impact of COVID-19 on school education: Are ed-tech companies really the panacea?. Contemporary Education Dialogue, 18 (1), 58-89.

[13] Karthikeyan, D. (2020). Assessing the effectiveness of Microsoft Teams during COVID-19 for online learning: A students' perceptive.

[14] Kim, H. (2020). The Efficacy of Zoom Technology as an Educational Tool for English Reading Comprehension Achievement in EFL Classroom. International Journal of Advanced Culture Technology, 8 (3), 198-205.

[15] Kohnke, L., \& Moorhouse, B. L. (2020). Facilitating synchronous online language learning through Zoom. RELC Journal, 0033688220937235.

[16] Lenkaitis, C. A. (2020). Technology as a mediating tool: videoconferencing, L2 learning, and learner autonomy. Computer Assisted Language Learning, 33 (5-6), 483-509.

[17] Mohan, G., McCoy, S., Carroll, E., Mihut, G., Lyons, S., \& Mac Domhnaill, C. (2020). Learning for all? Second-level education in Ireland during COVID-19. Economic and Social Research Institute (ESRI) Research Series.

[18] Nash, C. (2020). Report on digital literacy in academic meetings during the 2020 COVID-19 lockdown. Challenges, 11 (2), 20.

[19] Orhan, G., \&Beyhan, Ö. (2020). Teachers' Perceptions and Teaching Experiences on Distance Education through Synchronous Video Conferencing During Covid-19 Pandemic. Social Sciences and Education Research Review, 7 (1), 8-44.

[20] Parra, O., \&Granda, M. F. (2021). Evaluating the Meeting Solutions Used for Virtual Classes in Higher Education during the COVID-19 Pandemic. In VISIGRAPP (2: HUCAPP) (pp.190-197). 
[21] Pokhrel, S., \& Chhetri, R. (2021). A literature review on impact of COVID-19 pandemic on teaching and learning. Higher Education for the Future, 8 (1), 133141.

[22] Tolga, G. O. K. (2015). The Evaluations of the College Students' Perceptions on Distance Education from the Point of the Technical and Educational Factors. Turkish Online Journal of Distance Education, 16 (2), 84-93.

[23] Bsharat, T. R., \&Behak, F. (2020). The Impact of Microsoft Teams' App in Enhancing TeachingLearning English during the Coronavirus (COVID19) from the English teachers' perspectives' in Jenin city. Malaysian Journal of Science Health \& Technology, 7.

[24] Wea, K. N., \& Kuki, A. D. (2021, March). Students' Perceptions of Using Microsoft Teams Application in Online Learning During the Covid-19 Pandemic. In Journal of Physics: Conference Series (Vol.1842, No.1, p.012016). IOP Publishing.

[25] Yu, L. T. (2018). Native English-Speaking Teachers' Perspectives on Using Videoconferencing in Learning English by Taiwanese Elementary-School Students. JALT CALL Journal, 14 (1), 61-76. 